economy, and in some cases may even overrepresent it. But governments have too often become the representatives of private corporate (rather than public) interests and are thus not performing this function adequately, leaving the commons underrepresented, undervalued and underprotected.

Barnes' basic recommendation is the creation of trusts to manage common property rights. An example is the Alaska permanent fund, a trust set up by the state of Alaska to manage royalty payments for oil and gas extraction. Other examples include the various land trusts, easements and concessions that have evolved and been used effectively by non-governmental organizations such as the Nature Conservancy and Conservation International. Barnes' vision would greatly expand these modest beginnings to cover all our common natural and social capital assets (while leaving private property intact). These common assets are estimated to be worth several times more than all the world's private assets combined (see Nature 387, 253-260; 1997).

A good example would be an atmospheric trust to manage carbon dioxide (and other air pollution) emissions. The various cap-andtrade systems proposed so far for $\mathrm{CO}_{2}$ would fit nicely into the trust scheme, especially if permits were auctioned to emitters, rather than given away free of charge. The trust would set the caps (reducing them over time), collect the auction fees (which would increase as the cap was reduced), and use the revenues to protect and enhance the asset (by investing in renewable energy, for example, or paying private landowners to sequester carbon). The trust could also distribute a fraction of the revenues to all citizens on a per capita basis, as Alaska does now with oil and gas royalties, in the form of tax credits and dividends. This would reverse the regressive nature of fees on carbon emissions because large emitters would pay more into the trust than they got back, whereas small emitters would get back much more than they pay in. On the global scale, this payment could also help to substantially alleviate poverty.

The details of how to pay individuals while avoiding bureaucratic corruption and excessive transaction costs would need to be worked out, of course, and this would be no mean feat. But this is just the kind of challenge that creative capitalists (version 3.0) would warm to.

Upgrading capitalism will not be without trauma (think of the last time you upgraded your computer system), but it is long overdue and is essential if the capitalist system is to survive another century. There are many devilish details to work out, but the upgrade is already under way and gaining momentum. Let's hope the system doesn't crash before it can be completed.

Robert Costanza is director of the Gund Institute for Ecological Economics, Rubenstein School of

Environment and Natural Resources,

University of Vermont, 617 Main Street,

Burlington, Vermont 05405-1708, USA.

\title{
Neurons and knowledge
}

\section{Second Nature: Brain Science and Human \\ Knowledge \\ by Gerald M. Edelman \\ Yale University Press: 2007. 203 pp. \\ $£ 16.99, \$ 24$}

\section{David Papineau}

In 1972, at the age of 43, Gerald Edelman won a Nobel Prize for his work on the molecular structure of antibodies. Since then he has written a series of books about the human mind, starting with Neural Darwinism (Basic Books, 1987) and including The Remembered Present (Basic Books, 1990), Bright Air, Brilliant Fire (Basic Books, 1992) and Wider than the Sky (Yale University Press, 2004). In his latest book, Second Nature, Edelman turns his attention to epistemology. His aim is "to ground the theory of knowledge in an understanding of how the brain works".

Epistemology, or the theory of knowledge, is traditionally the preserve of philosophers, and is a house with many mansions. At the start of modern philosophy, René Descartes aimed to show how our beliefs could be placed on absolutely firm foundations. More recently, philosophers have become suspicious of Descartes' aspirations to certainty. As a result, many now agonize about how we should define 'knowledge' if it doesn't require certainty. Others seek to develop epistemology as part of probability theory, analysing the relation between evidence and estimates of the likelihood of events. And there are others still who see epistemology as an essentially practical enterprise whose task is to sift accurate modes of thought from unreliable ones.

Edelman sees little value in any of these philosophical efforts. He dismisses most of them as "armchair operations" that are not empirically testable. Even the more practically minded philosophers are criticized for ignoring the 'neural underpinnings' of knowledge. In Edelman's view, only a 'brain-based epistemology' will yield real results. In principle this sounds like an exciting project, but in the end the book is disappointing. Edelman covers a lot of ground in relatively few pages, but it is not always clear what he is trying to say.

The first few chapters focus on consciousness, on the not unreasonable grounds that knowledge presupposes consciousness. As will be familiar to readers of his previous books, Edelman takes consciousness to depend on 're-entrant activity' resulting from reciprocal signalling between different regions of the brain. It is hard to know what to make of this theory. Unsympathetic critics will ask what distinguishes re-entrant activity from the feedback projections that are familiar to all brain researchers. We might also ask how the theory measures up to Edelman's own high standards of scientific testability. For example, his theory implies that frogs are not conscious, as they lack sufficiently complex brains. But how are we to test this claim, in the absence of any independent criteria for frog consciousness?

When Edelman turns to knowledge itself, he is not much more explicit. Early on he promises "an account of knowledge that relates truth to opinion and belief, and thought to emotion by 
in response to experience. Edelman explains how these devices can learn to recognize patterns and navigate new environments. This is intriguing, but it is rather difficult to assess its significance in the absence of any comparison with other learning-based robotics research.

This lack of scientific comparisons is a striking feature of the book. A naive reader could easily form the impression that Edelman and his associates are the only people trying to use scientific information to cast light on the human mind. Not that the book lacks references: it is full of brief digests of philosophical and cultural figures, such as Wilhelm Dilthey, Ludwig Wittgenstein, Isaiah Berlin, Richard Rorty and many more. It is impressive that Edelman should have read their work, but I couldn't help wondering who his own book was written for. Is there really a readership for potted cultural history written by senior scientists? In any case, this is not a book for those who want to know how brain science relates to epistemology.

David Papineau is professor of the philosophy of science, King's College London, London WC2R 2SL, UK. He is the author of Thinking About Consciousness (Oxford University Press, 2002).
FILM

\section{Dark days ahead}

\section{Sunshine}

directed by Danny Boyle, written by

Alex Garland

Twentieth Century Fox. Worldwide release from 6 April 2007

\section{Richard Webb}

"Our Sun is dying," intones a laconic voiceover at the start of the film Sunshine. Why, in the year 2057, Earth's star is failing is unspecified. Astrophysical orthodoxy would demand that life on Earth is extinguished by the Sun's red-giant phase long before its light fades away - and that only in billions of years' time. But as Brian Cox, a researcher at the particlephysics laboratory CERN who acted as scientific consultant to the film, was at pains to point out in the pre-release publicity, there is still a lot we don't know about the Universe. The cosmos, like the cinema, is a medium of infinite surprises.

Not that Sunshine, at least in its basic scenario, is surprising at all. This is cinematic déjà vu: with humanity's survival threatened, a group of brave, bright young things must take up arms for all our sakes. The eightman crew of the spaceship Icarus II has been charged with restarting the Sun. They have to drop a nuclear payload - fissile material amounting to the mass of Manhattan - into its core. A first attempt, Icarus I, has failed, with all contact having been lost seven years before.

Early enough in this second, last-gasp mission, a law of cinema as ineluctable as the law of gravity kicks in: what goes up never looks like coming down. Icarus II's calamities begin as it prepares for the slingshot round Mercury that will propel it into the Sun's corona: it picks up a distress signal from Icarus I. Diverting course towards their lost predecessor engenders a chain of events that puts both mission and crew in mortal danger.

But like Icarus II, the film manages to diverge from its preordained trajectory. Despite its big-budget look and feel, this is a (relatively) cheap-and-cheerful British production, which frees it from some of the more egregious demands of Hollywood schmaltz. In particular, its commitment to a happy ending is equivocal; each setback to the mission also demonstrably reduces the crew's own chances of survival. "There will be no ticker-tape parade," says Mace, the hard-boiled engineer, with bitter resignation as a particularly cruel sideswipe of fate blows out most of the ship's oxygen. That fatalistic undercurrent makes for an interesting study of human interactions in a - literally and metaphorically - pressurized environment.

Science is handled pleasingly well in Sunshine. Scientific vocabulary is not flung about with the gay, context-free abandon that is traditional in such circumstances. Before shooting the film, Cillian Murphy, who plays physicist Capa, guardian of Icarus II's nuclear payload, visited CERN to observe real physicists in their natural habitat. The gratifying (if somewhat surprising) result is a scientist on the silver screen who seems manifestly sane. It is true that when I worked at CERN, none of my physicist colleagues there had quite such rippling biceps, nor did they pout in the face of adversity quite so provocatively as Capa. But this much can be forgiven in the exercise of creative licence.

As Sunshine and Icarus II hurtle ever faster to their destination, the plot's twists lean ever more towards the demands of cinema than those of solid science. But you don't go to a blockbuster film to be entertained by two hours of fastidiously researched plausibility: wall-towall action, searing special effects, a messianic score and fine acting are generally more than adequate compensation. Sunshine has these in abundance.

And yet this film has only one true star: the Sun's yellow-orange plasma, a constant, hypnotic backdrop shown off to full advantage in an early scene as the ship's crew watches the tiny black silhouette of Mercury transit across its shimmering face. At a time when we are ever more concerned with Earthbound threats to humanity's survival, such images are an aweinspiring tribute to a power of nature that will, in time, be the death of Earth. Five billion years' hence, however, we probably shan't be around to rage against the dying of the light.

Richard Webb is Nature's physics News \& Views editor.

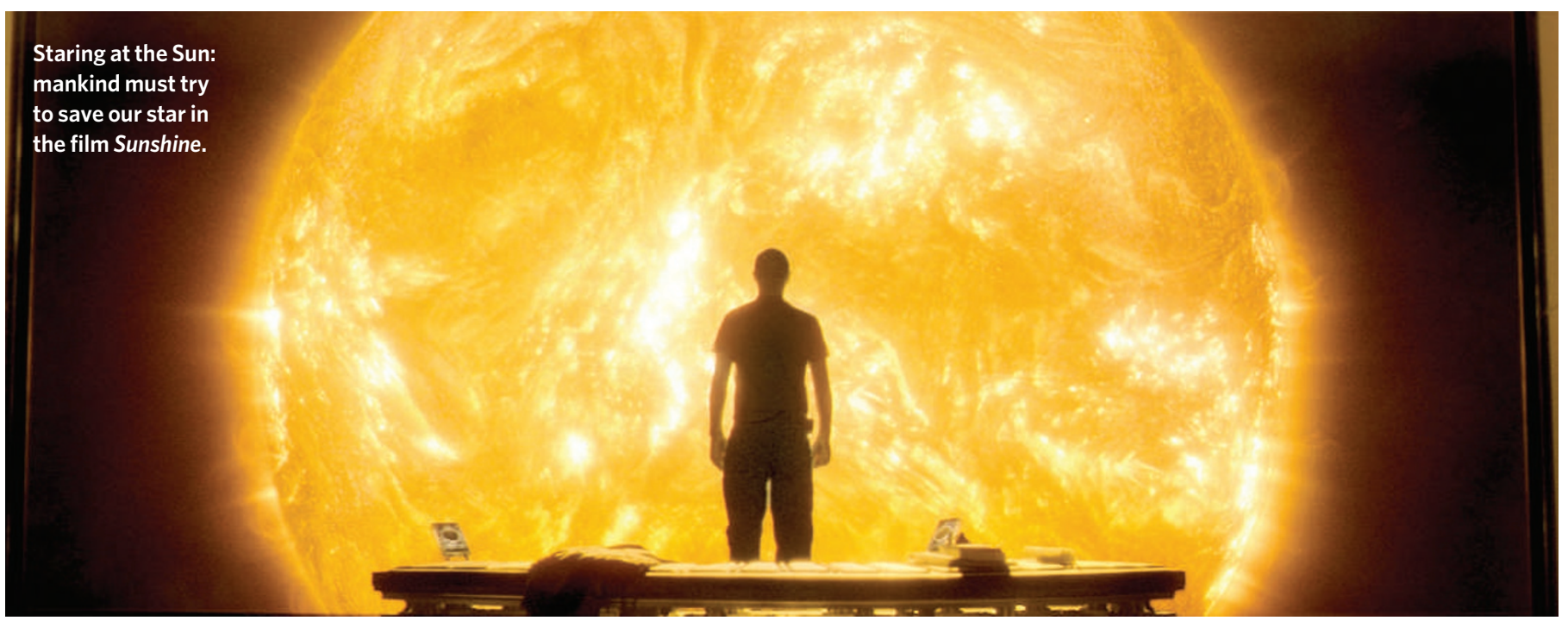

